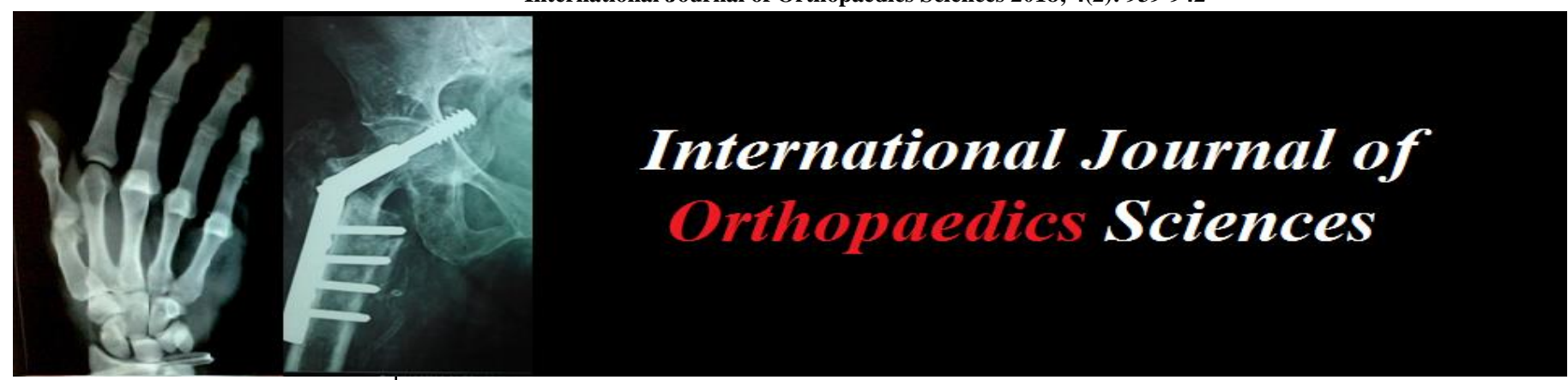

ISSN: $2395-1958$

IJOS 2018; 4(2): 939-942

(C) 2018 IJOS

www.orthopaper.com

Received: 13-02-2018

Accepted: 14-03-2018

Dr. Kishorchand Naorem

Department of Orthopaedics, RIMS, Imphal, Manipur, India

Dr. Temjensunep

Department of Orthopaedics, RIMS, Imphal, Manipur, India

Correspondence

Dr. Kishorchand Naorem

Department of Orthopaedics,

RIMS, Imphal, Manipur, India

\section{Treatment of forearm fractures in children and adolescents with titanium elastic nails (Tens): A prospective study}

\section{Dr. Kishorchand Naorem and Dr. Temjensunep}

DOI: https://doi.org/10.22271/ortho.2018.v4.i2n.133

Abstract

Paediatric forearm fractures are generally treated nonoperatively by close reduction and casting. Recently there has been trend on intramedullary nailing of diaphyseal forearm fractures for unstable fracture pattern to impove clinical outcomes. In our study we evaluated the rate of fracture union, functional outcome and complications in forearm fractures of children and adolescents treated with titanium elastic intramedullary nails. All cases achieved union within 16 weeks and excellent functional outcome after surgical management without significant complications. Intramedullary nailing with Titanium elastic nails is a feasible and effective method of treatment for unstable diaphyseal fractures of forearm in children and adolescents.

Keywords: Forearm fracture fixation, both bone forearm fracture, TENS, children and adolescents

\section{Introduction}

Fractures of the both bones forearm are very common orthopaedics injuries in the pediatric age group. Forearm fractures comprises $40 \%$ or more of paediatric fractures ${ }^{[1]}$. The mechanism of injury mostly involves a fall onto an outstretched hand. Majority of the fractures are usually treated conservatively with plaster casting. For displaced and unstable forearm fracture where closed reduction cannot be achieved, surgical intervention is indicated like rigid plate fixation and elastic intramedullary nails. Recently, however, there has been a trend towards increased surgical management of these fractures in an effort to improve clinical outcomes ${ }^{[2]}$. Elastic intramedullary nails were originally developed in the early 1980s by surgeons in Nancy, France ${ }^{[3,4]}$. There has been an increased interest in determining which method provides superior results, but the optimal treatment remains controversial ${ }^{[5]}$.

Forearm fracture fixation with flexible nails has gained popularity, with proponents arguing that nailing results in decreased surgical dissection and retention of biologic factors at the fracture site ${ }^{[6,7]}$. Both titanium and stainless steel flexible nails are available. In the clinical setting, titanium ( $\mathrm{Ti} 6 \mathrm{~A} 114 \mathrm{~V}$ ) is being used more often than stainless steel in most circumstances because of the elastic properties which allow for improved insertion and rotation while still providing adequate fracture stabilization ${ }^{[8]}$.

\section{Materials and Methods}

30 patients aged between 5 and 18 years with diaphyseal forearm fractures (Fig 1) treated with tens between October 2015 and September 2017 were included in this prospective study. No patients were lost to follow-up. 20 pateints $(66.66 \%)$ were in the age group of 5-10 years and $10(33.33 \%)$ were in the age group of $10-15$ years. There were 22 males $(73.33 \%)$ and 08 females (26.67\%). 19 patients $(63.33 \%)$ had right sided fractures and $11(36.67 \%)$ had left sided fractures. Bilateral forearm fractures were not encountered in the study. 21 cases (70\%) were attributed to accidental fall, road traffic accident accounted for 5 (16.67\%) cases and fall from height accounted for $4(13.33 \%)$ of the cases. 19 of the fractures were transverse fractures $(63.33 \%), 7$ were oblique fractures $(23.33 \%), 4$ were segmental fractures $(13.33 \%)$ and there were no comminuted fractures. 


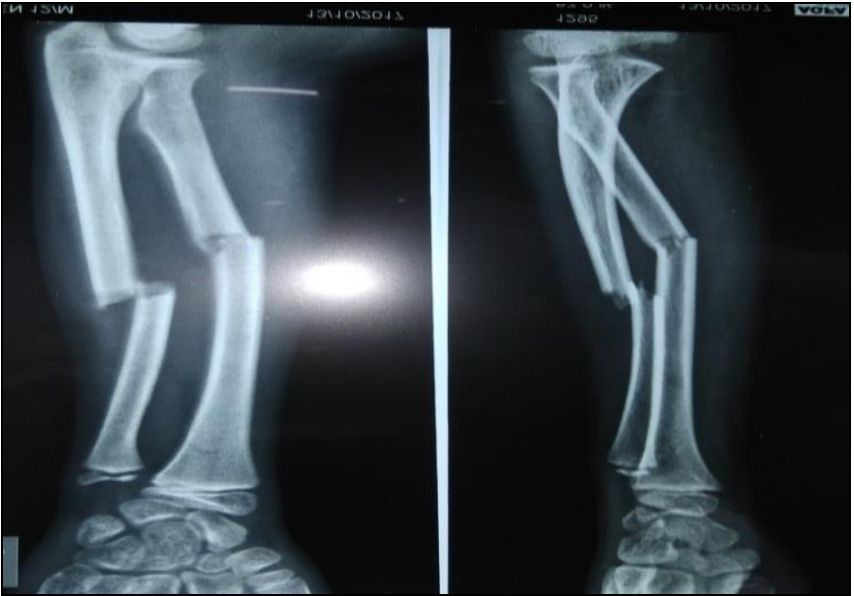

Fig 1: Radiograph showing both bone forearm fractures

All postoperative patients were reviewed for clinical outcome and radiographs over a 24-month period. Radiographs of the immediate post-operative period was compared with that of final follow-up. The union of fracture was assessed by callus formation and disappearance of fracture lines radiologically and absence of pain and tenderness clinically. Patients were followed up for a period of one year at regular intervals, once in every four weeks for the first three months after surgery, then once in six weeks for the next three months and then at the final follow up. Angular deformity was measured on antero-posterior and lateral radiograph. Range of movements of forearms was assesed and compared with the uninjured limb. Functional outcome was evaluated using Price et al. criteria ${ }^{[9]}$.

Price et al. grading criteria

\begin{tabular}{|c|c|c|}
\hline Outcome & Clinical & Rom \\
\hline Excellent & No complaints with activity & $\begin{array}{c}\text { Loss of 10 degrees of } \\
\text { ROM (FA rotation) }\end{array}$ \\
\hline Good & $\begin{array}{c}\text { Minor complaints with } \\
\text { strenuous activity }\end{array}$ & $\begin{array}{c}\text { Loss of 11-30 degrees of } \\
\text { ROM }\end{array}$ \\
\hline Fair & $\begin{array}{c}\text { Minor complaints during } \\
\text { normal daily activities }\end{array}$ & $\begin{array}{c}\text { Loss of 31-90 degrees of } \\
\text { ROM }\end{array}$ \\
\hline Poor & Major complaints & $\begin{array}{c}\text { Loss of 90 degrees of } \\
\text { ROM }\end{array}$ \\
\hline
\end{tabular}

\section{Operative technique}

Under general anesthesia the affected limb is placed on a lateral table and a pneumatic tourniquet is positioned if open reduction is required. A $1-\mathrm{cm}$ long longitudinal skin incision was made on the lateral side of the distal metaphysis of the radius. With a bradawl, a hole is drilled in the bone proximally to the metaphysis, first perpendicularly and then obliquely toward the elbow. Depending on the diameter of the bone, we choose a flexible titanium nail of appropriate size and the proximal end is bent 30 degrees. The nail is introduced proximally into the radius with bent side first and pushed, with a hammer if necessary, to the fracture site. The fracture is reduced by external manipulation, and the pin is advanced into proximal metaphysis. A similar incision is made over the posterior olecranon and a small entry hole is drilled and passed the nail across the fracture site distally. The outer tips of the nails is bent and cut 5 to $10 \mathrm{~mm}$ from the entry point (Fig 2 and 3). The wound is closed with one or two stitches.
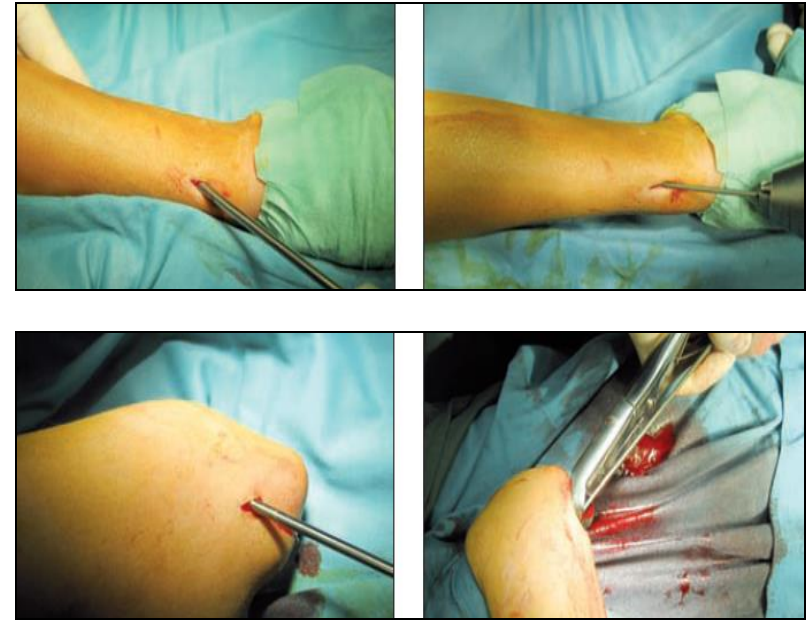

Fig 2: Intra operative images showing insertion of nails

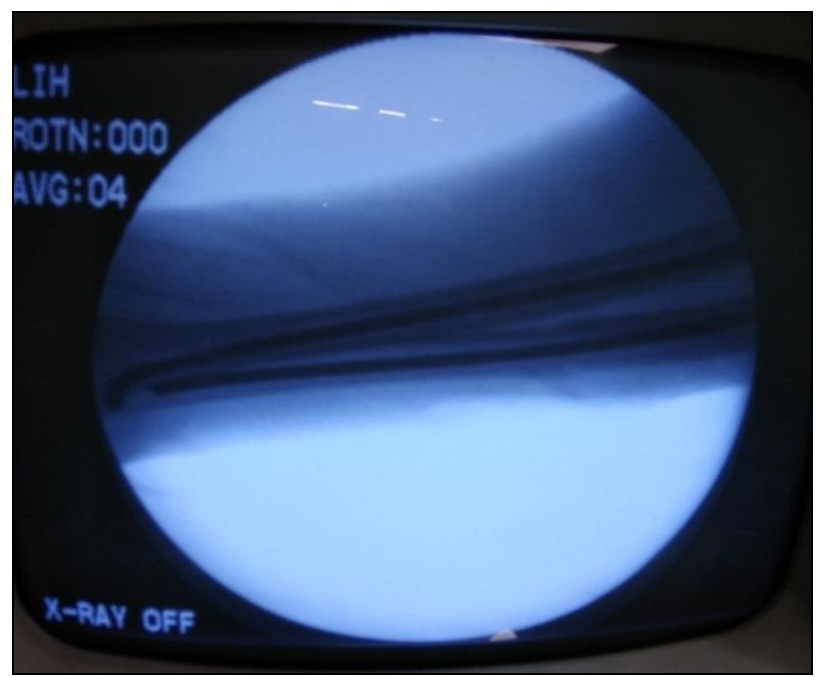

Fig 3: Reduction confirmed using $\mathrm{C}$-arm image intensifier

The operated limb is kept elevated and active finger exercises encouraged as soon as the patient recovered from the anaesthesia. Stitches were removed on the 10th day and patients were discharged with plaster of paris (POP) slab continued for another 3 weeks. At 3 weeks after the operation POP slab was removed and mobilising exercises started. Implant removal was done after 3 months of the operative procedure when radiological evidence of osseous union seen.

\section{Results}

Radiograph analysis of preoperative and postoperative and final follow radiograph was performed. All cases achieved clinical and radiologic union after surgical management (Fig 4). All fractures united by the 16 weeks (Fig 5) and there were no case of non-union, mal-union, wound infection or refracture. $26(86.67 \%)$ patients regained full range of motion, $3(10 \%)$ patients had mild restriction of movements and 1 (3\%) patient had moderate restriction of movements. No patient were observed to have severe range of movement restriction (Fig 6). Functional score according to Price et al, there were 24 excellent, and 6 good results. 


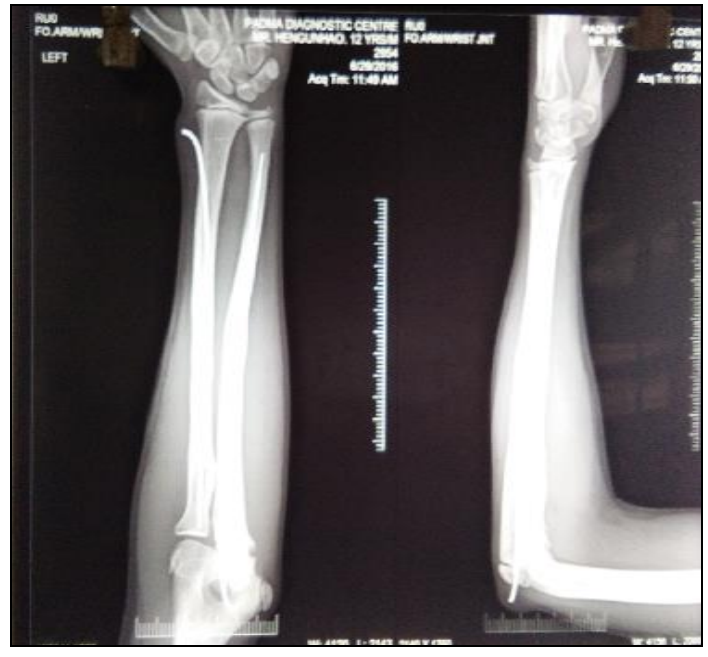

Fig 4: Radiograph showing union at

\begin{tabular}{|c|c|c|}
\hline $\begin{array}{c}\text { Time in weeks for union } \\
\text { of the fracture }\end{array}$ & $\begin{array}{c}\text { Number of patients } \\
\text { showing union }\end{array}$ & $\begin{array}{c}\% \\
\text { (Percentage) }\end{array}$ \\
\hline $10-12$ weeks & 18 & 60 \\
\hline $12-14$ weeks & 10 & 33.33 \\
\hline$>14$ weeks & 2 & 6 \\
\hline Total & 30 & $100 \%$ \\
\hline
\end{tabular}

Fig 5: Time of fracture union 12 weeks
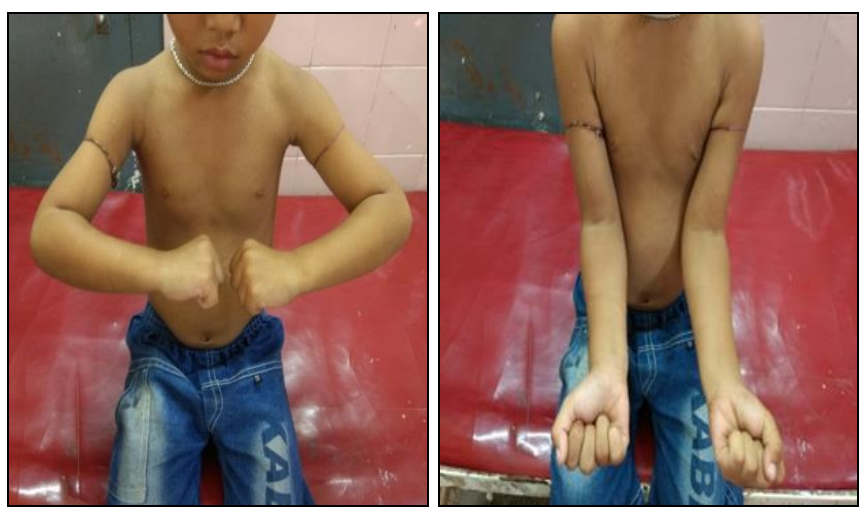

Fig 6: Range of movements at final follow up

\section{Discussion}

Majority of the diaphyseal forearm fractures are usually treated conservatively with plaster casting. Unstable fractures which are unamendable to close reduction to an acceptable alignment, surgical management is recommended. Recently elastic intramedullary nails are increasing popular for the treatment of forearm fractures which mimimise surgical scarring previously caused by traditional open reduction and plating.

Barry $\mathrm{M}$ et al. regarded intramedullary nailing is safe, minimally invasive, appeared to have few complications, does not interfere with growth, and is associated with short hospital stays and a rapid return to daily activity. Celebi L et al. ${ }^{[10]}$ assessed the results of intramedullary nailing in children who developed re-displacement during cast treatment of both-bone forearm fractures, and came to a conclusion that intramedullary fixation for correction losses during cast treatment of both-bone forearm fractures is a safe and inexpensive treatment, allowing early mobilization and providing excellent anatomic and functional results. Mohammed $\mathrm{H}$ et al. ${ }^{[11]}$ conducted a retrospective review of 21 children with unstable forearm fractures treated with flexible intramedullary nail fixation. Intramedullary nail fixation of both bones was performed in 17 patients, radius in
3 cases, and ulna in one case. A limited open approach to one or both bones was necessary for insertion of the intramedullary nail in 12 cases. The two complications that occurred were delayed union and mild limitation of forearm motion. However, the functional outcome was excellent. It is recommended to use this technique for unstable pediatric forearm fractures instead of open reduction and plating. Shah AS et al. ${ }^{[12]}$ conducted a retrospective comparative study on sixty-one skeletally immature adolescents (mean age, 13.9 years; range, 11.5-16.9 years) treated operatively for bothbone forearm fractures from 1997 to 2007, and concluded that, flexible IM nailing of both-bone forearm fractures in adolescents was safe and effective in their small series; had less complications when compared with conventional ORIF. Although flexible IM nailing results in distal translation of the radial bow, forearm rotation is not compromised.

Alnaib M et al. ${ }^{[13]}$ reported both-bones intramedullary nailing is a minimally invasive procedure that maintains alignment and promotes rapid bony healing. They reported their experience in treating these common injuries with radius only intramedullary nailing in 29 children. All fractures achieved clinical and radiological union at 6-8 weeks. Radius only intra medullary nailing is a sufficient and effective option in treating both bones paediatric forearm displaced unstable type AO 22-A3 fractures, with excellent functional outcome and union rates. Furlan D et al. ${ }^{[14]}$ demonstrated the effectiveness of intramedullary fixation of displaced long bones shaft fractures in skeletally immature children using the elastic stable intramedullary nails, and concluded that, elastic stable intra-medullary nailing is the method of choice for pediatric patients, because it is minimally invasive and shows very good functional and cosmetic results. It allows an early functional and cast-free follow-up with a quick pain reduction. Salonen A et al. ${ }^{[15]}$ conducted a retrospective study on 75 children, who were treated for antebrachium shaft fractures from January 2001 to December 2005, and concluded that, despite various minor complications, TENSnailing is considered a suitable treatment for unstable forearm shaft fractures. Wall L et al. ${ }^{[16]}$ conducted a retrospective study on 32 patients (12-18 years of age) who had undergone intramedullary fixation of both forearm bones and reported Flexible intramedullary nailing of both bone forearm fractures provides reliable bony union and excellent postoperative clinical results in adolescents.

Vopat ML et al. ${ }^{[17]}$ stated severe comminution and bone loss should be considered as indications for plate fixation, while intramedullary nailing offers better cosmesis, and decreased soft tissue disruption. Haoqi Cai et al. ${ }^{[18]}$ conducted a study on 52 children aged between 4-14 years and showed that the application of prebent elastic intramedullary nail is a good method to treat DRDMJF (distal radius diaphyseal metaphyseal junction fracture), with a satisfactory alignment, stable fixation, and less migration.Chen CE et al. [19] recommended that intramedullary nailing with TENS should be the treatment of choice for skeletally immature children with displaced forearm fracture requiring internal fixation.

In a prospective analysis by Shivanna et al. ${ }^{[20]}$ of diaphyseal forearm fractures in children treated with titanium elastic nails excellents results were reported in $96 \%$ without significant complications after a mean follow up of 20 period.

\section{Conclusion}

It can be concluded from this study, that intramedullary nailing with Titanium elastic nails is a feasible and effective method of treatment for unstable diaphyseal fractures of 
forearm in children and adolescents. It provides stable fixation, better cosmesis with excellent functional outcome over traditional plating methods.

\section{References}

1. Jones K, Weiner DS. The management of forearm fractures in children: a plea for conservatism. J Pediatr Ortho. 1999; 19:811-5.

2. Flynn JM, Jones KJ, Garner MR, Goebel J. Eleven years' experience in the operative management of pediatric forearm fractures. J Pediatr Ortho. 2010; 30:313-9.

3. Barry M, Paterson JM. A flexible intramedullary nails for fractures in children.J Bone Joint Surg Br. 2004; 86:94753.

4. Ligier JN, Metaizeau JP, Prevot J. Closed flexible medullary nailing in pediatric traumatology. Chir Pediatr. 1983; 24:383-5.

5. Abraham A, Kumar S, Chaudhry S, Ibrahim T. Surgical interventions for diaphyseal fractures of the radius and ulna in children. Cochrane Database Syst Rev, 2011, 11. Art. No.: CD007907

6. Sinikumpu JJ, Pokka T, Serlo W. The changing pattern of pediatric both-bone forearm shaft fractures among 86,000 children from 1997 to 2009. Eur J Pediatr Surg. 2013; 23:289-96.

7. Prevot J. Stable elastic nailing. ZUnfallchir Versicherungsmed Berufskr. 1989; 82:252-260.

8. Lascombes P, Haumont T, Journeau P. Use and abuse of flexible intramedullary nailing in children and adolescents. J Pediatr Ortho. 2006; 26:827-34.

9. Price CT, Scott DS, Kurzner ME. Malunited forearm fractures in children. J Pediatr Ortho. 1990; 10:705-712.

10. Celebi L, Muratli HH, Doğan O, Yağmurlu MF, Akşahin $\mathrm{E}$, Biçimoğlu A. The results of intramedullary nailing in children who developed redisplacement during cast treatment of both-bone forearm fractures. Acta Orthop Traumatol Turc. 2007; 41(3):175-82.

11. Haider Mohammed, Fareed Salloom, Mohammed Albagali, Ismail Aljahromy. Flexible Intramedullary Fixation of Pediatric Forearm Fractures-Report on twenty-one patients, Bahrain Medical Bulletin, 2009, 31(1).

12. Shah AS, Lesniak BP, Wolter TD, Caird MS, Farley Vander FA, Have KL. Stabilization of adolescent bothbone forearm fractures: a comparison of intramedullary nailing versus open reduction and internal fixation, J Ortho Trauma. 2010; 24(7):440-7.

13. Mustafa Alnaib, Razvan Taranu, Sandesh Lakkol, Ehab Aldlyami, Ilhan Alcelik, Christopher Tulloch. Radiusonly intramedullary nailing for both-bones diaphyseal forearm fractures in children, Acta Ortho. Belg. 2011; 77:458-463.

14. Furlan D, Pogorelic Z, Biocic Juric, Budimir D, Todoric $\mathrm{J}$, Mestrovic $\mathrm{J}$ et al. Elastic stable intramedullary nailing for paediatric long bone fractures: experience with 175 fractures, Scandinavian Journal of Surgery. 2011; 100(3):208-215.

15. Salonen A, Salonen H, Pajulo O. A critical analysis of postoperative complications of antebrachium TENSnailing in 35 children, Scand J Surg. 2012; 101(3):21621.

16. Wall L, O'Donnell JC, Schoenecker PL, Keeler KA, Dobbs MB, Luhmann SJ et al. Titanium elastic nailing radius and ulna fractures in adolescents. J Pediatr Ortho B. $2012 ; 21(5): 482-88$.
17. Matthew L, Vopat Patrick M, Kane Melissa A, Christino Jeremy Truntzer, Philip McClure, Julia Katarincic et al. Treatment of Diaphyseal Forearm Fractures in Children, Ortho Rev (Pavia). 2014; 6(2):5325.

18. Haoqi Cai, Zhigang Wang, Haiqing Cai. Prebending of a Titanium Elastic intramedullary Nail in the Treatment of Distal Radius Fractures in Children Int. Surg. 2014; 99(3):269-275.

19. Chin-En Chen1, Rei-Jahn Juhn, Fu-Jen Elastic. Intramedullary Nailing for the Treatment of Displaced diaphyseal forearm fractures in children, Journal of Medicine. 2014; 12(3):171-177.

20. Shivanna. In J Res orthop. 2016; 2(3):143-147. 